\title{
Psychological influences on biosecurity control and farmer decision-making. A review
}

\author{
Aditi Mankad ${ }^{1}$ \\ Accepted: 19 May 2016 / Published online: 7 June 2016 \\ (C) INRA and Springer-Verlag France 2016
}

urgent research and policy consideration. An exploratory model is presented for future research and on-the-ground considerations, incorporating psychosocial influences on decisionmaking and potential mediating factors.

Keywords Norms · Cognitions · Horticulture $\cdot$ Behaviour · Risk

\section{Contents}

1. Introduction

1.1 The psychology of biosecurity

2. Attitudes and perceptions

2.1 Risk attitudes

2.2 Social incentives, social norms and diffusion

3. Motivation and adherence

3.1 Protection motivation

4. Emotion, stress and attachment

5. Cognitive bias

5.1 Cognitive dissonance

6. Socio-contextual factors

7. Summary and implications for a social-psychological model of biosecurity engagement behaviour

7.1 A hypothesised model of farmer risk decisionmaking

8. Conclusion

9. Acknowledgments

10. References

\section{Introduction}

Biosecurity is broadly defined as the protection of public health, environment and economy against negative impacts associated 
with pests and disease within food and agricultural systems (Department of Primary Industries 2013; Food and Agriculture Organization of the United Nations 2013). In recent years, the potential for biosecurity threats to impact agriculture and food production has increased, as greater urbanisation and the movement of humans across the globe allow pests to migrate more easily than ever before via human transmission, clothing and particulars. Also, as modern trade intensifies, so too do pathways for spreading plant and animal pests and diseases. Biosecurity as it is defined here is a relatively modern concept; therefore, it is constantly evolving as new information feeds into the knowledge structure. However, a modern understanding of biosecurity around the world consistently incorporates the notion of shared responsibility and strategic integration of effort within its definition which reflects the need for national and global action. The United Nations' biosecurity strategy, too, calls for the improved coordination amongst national bodies to enforce 'sanitary, phytosanitary and zoosanitary' measures to prevent and/or manage hazards while ensuring trade is not negatively affected (Food and Agriculture Organization of the United Nations 2009).

In the context of agricultural and plant biosecurity, the idea of shared responsibility advocates the need for biosecurityrelated activities to be coordinated between and across all facets of food production, from individual-level on-farm behaviours to the area-wide transportation of goods, and the responsibilities of the general public living near places of production. Poor management of biosecurity risks can lead to threats to human health, such as contamination of food products through pest and disease treatments, ingestion of pathogen-contaminated foods and respiratory problems associated with problematic weed species (Heymann 2005; Department of Primary Industries 2013). The negative economic impacts of poor biosecurity on productivity and industry-level consequences are also exacerbated by subsequently stringent market protocols in place and strict restrictions on the trade of goods from regions known to have prevalence of a pest or disease in legislation and international agreements.

Qualitative evidence suggests that not all farmers comply with recommended biosecurity protocols for risk protection and management. A report by the Australian government, for example, cited a significant gap in current biosecurity engagement in terms of adequate monitoring and evaluation of threat, risk and on-farm practices (Kruger et al. 2009). There also seems to be a reactive decision-making culture amongst growers in the context of biosecurity. That is, rather than having a regulated and consistently managed program to deal with potential threat(s), growers will only change their practices in response to an immediate threat, rather than engaging in protective behaviours to prevent a threat. Further, the focus of protective biosecurity action tends to be on threats that are known, rather than risks posed by those pests and/or diseases which may not yet be in Australia; prompting behaviour that targets the latter is a particularly difficult message to convey, especially to the general public who may be exhibiting highrisk behaviours such as not declaring produce or goods sourced overseas (Beale et al. 2008; Kruger et al. 2009). Such behaviour can be stressful and costly to individual growers, as they are suddenly required to pest-proof their farm very quickly and usually at a high and acute cost.

As Pannell et al. (2006) explain, farmers do readily adopt some new practices on-farm, when they benefit to the actions (e.g. Fig. 1); however, they can see a clear financial and practical benefit to the actions; however, they are harder to convince when benefits are less immediately tangible. This is because of the significance and complexity of daily decisions that compete for a farmer's time and all of which consume valuable attentional and emotional resources, leaving little cognitive energy to consider issues that appear less time-sensitive.

\subsection{The psychology of biosecurity}

The key psychological issues to consider when examining onfarm biosecurity and decision-making are as follows:

- On-farm behaviours are based on pre-existing subjective knowledge and they are learned behaviours that have become habitual; therefore, they are open to change but require a psychological shift.

- Individuals must have the resilience to persevere (adhere) to changed practices in order to properly control and potentially eradicate the pest or disease.

- Practicing biosecurity has implications for the individual, as well as others (social aspect).

- Farmers must see the relevance and necessity of biosecurity-relevant behaviours and feel that it is worth their time and involvement.

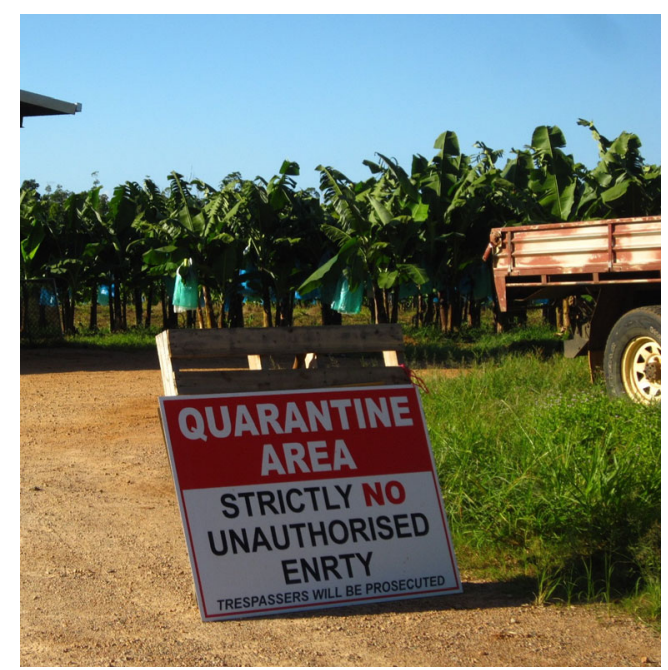

Fig. 1 Biosecurity in action on an Australian banana plantation. Image source: Dr. Matthew Curnock, CSIRO 
- Growers must trust that the dominant administrative bodies are reliable sources of information and they can be trusted to manage biosecurity initiatives.

For many farmers, asking them to adopt unfamiliar or alternative practices is a serious request, as they have likely spent years developing a set of systems and routines that work best for their business and their land. To shift away from these habitual behaviours sometimes requires a shift in attitudes and perceptions to convince individuals that a change is necessary and beneficial. One's psychological preparedness and decisionmaking capacity is what distinguishes groups of growers and the adoption of novel biosecurity practices. There is also a clear financial incentive to be proactive regarding biosecurity, because effective biosecurity management can mitigate production losses and monetary consequences of poorly managed threats to food production (Abdalla et al. 2012; Hoe and Ruegg 2006). However, not all farmers engage in behaviours that reflect best practice or control in terms of biosecurity. While quality assurance programs and guidelines for best management practices exist in multiple food production industries, farmers broadly remain uneducated about the potential severity of, and vulnerability to, relevant biosecurity risks.

When breaking down 'biosecurity' to the behavioural level, it becomes clear that there are dominant psychological issues relevant to behavioural uptake and adherence to onfarm practices and the psychological factors that drive the decision to enact protective behaviours. Often, people have long-term habits that are resistant to behaviour change initiatives, which can limit the effectiveness of risk management interventions. Pre-existing beliefs and attitudes about management practices and/or the spread of disease can also influence people's perceived vulnerability to certain biosecurity risks. This affects growers' confidence in their ability to engage in mitigation behaviours and the risk-related activities they consequently engage in (Bish and Michie 2010).

Past research on attitudes and perceptions specific to the biosecurity domain has predominantly been conducted in the animal industry, examining issues such as foot and mouth disease, equine influenza and other diseases found in commercial animal production (Buetre et al. 2013; Hoe and Ruegg 2006; Schemann et al. 2011). Results have typically demonstrated that farmers perceive the level of investment required to implement biosecurity practices on-farm as costly, in terms of both financial cost and effort. Inherent in this finding is an assumption that, at the core, some farmers are not convinced that increased biosecurity management efforts and improvements to physical systems on-farm (e.g. increased fencing, wash-down facilities) are worth this increased commitment. Rather, there are day-to-day pest and crop management issues that take precedence over a preventative biosecurity measure for a disease or pest that may or may not be a threat. A further barrier to widespread biosecurity practices is trusting a taxonomic diagnosis of a disease or pest. A misdiagnosiseither personal or vicarious - can reduce trust in the reporting systems and weaken intentions to report future biosecurity threats and a reduced uptake of protective behaviours.

While the key players responsible for biosecurity control might include farmers, peak industry bodies and governments, it is widely accepted that farmers remain at the forefront of disease prevention. Farmers are best placed to manage risks and implement protective on-farm practices, as well as financially benefitting most from disease control (e.g. Department for Environment Food and Rural Affairs 2014; Plant Health Australia 2011; Scottish Executive 2002). However, not all farmers will view a biosecurity threat in the same way and, thus, will experience varying levels of motivation to engage in protective behaviour. This creates a tenuous social environment in which individual cognitions and motivations around appropriate biosecurity risk responses come into play. Further, complexities surround the definition of a biosecurity incursion and ownership of biosecurity practices will likely influences decision-making. Thus, a 'shared' approach to biosecurity management may give way to a potentially fractious social environment where some growers feel as though they are investing more time, money or effort into a biosecurity response while others are seen as taking on less of the share (Enticott and Vanclay 2011).

This discussion paper hypothesises that, while farmers know that biosecurity protection is important and are aware of potential benefits of risk management strategies on their farms, there exist significant social and psychological factors influencing the interpretation of risk and the ultimate adoption (or non-adoption) of risk management behaviours at the individual-level. The methodology for this review was to search the broader biosecurity and agricultural literature where biosecurity, behavioural adoption and social-psychological principles were specifically discussed. While some broad social reviews exist relating to adoption of new practices in the agricultural context (e.g. Pannell et al. 2006), this paper purposefully examines research which illustrates the importance of understanding biosecurity decision-making through a psychological lens. This allows a more nuanced discussion of underlying cognitive and motivational processes that may be occurring during biosecurityrelevant decision-making, and what psychological factors could be targeted for future behaviour change initiatives.

\section{Attitudes and perceptions}

Hogg and Vaughan (2005) define attitudes as an enduring organisation of beliefs, feelings and behavioural tendencies towards objects, events, individuals or groups. The function of attitudes is to provide evaluative information and this can be positive, negative or uncertain; attitudes are an important area of study in psychology because they help to determine 
what people do and why they do it. There are three psychological components that comprise attitudes: affective, behavioural and cognitive. The affective component of an attitude is one's emotional reaction to the target object, event or person, and this influences how the target is cognitively perceived. The cognitive component represents the thoughts and beliefs about the target object/event/person(s). Finally, the behavioural component of attitudes then describes how an individual might react or respond when exposed to the target object. If we use the example of a peach grower and her attitudes towards Queensland fruit fly, we can hypothesise that for this grower, thinking about or experiencing a fruit fly pest incursion may elicit negative emotions such as frustration, anger or worry, which causes the farmer to feel a certain way when exposed to the target (affective response). This is because the grower believes the pest can spoil her crops and hinder the ability to profit from her business (cognitive component). Thus, the peach grower may use natural or biological strategies to eradicate the pest from her property based on personal beliefs about how best to deal with fruit fly (behavioural response). The farmer's attitude, in combination with other factors, will also influence her biosecurity behaviour in the future, for example, her choice to address each fruit fly incursion as it happens or implement strategies to mitigate an invasion risk before it happens. This will likely depend on the disease or pest specificity; that is, factual characteristics of the pest itself such as whether it is eradicable/non-eradicable, species reproduction, etc. Thus, by breaking down the psychological stages of decision-making, we can start to understand why farmers may or may not choose to engage in or adhere to biosecurity management practices.

The significance of an attitude is dependent upon its importance and personal relevance. For example, attitudes towards fruit fly control techniques would be significant to our peach grower because it is a highly salient topic with self-interest for the grower, as well as the groups she may be a member of. In contrast, attitudes towards fruit fly are unlikely to be as salient for a cotton farmer, as fruit fly does not influence the cotton farmer's crops in a significant way, or affect his/her life or personal values in the same way it would a peach grower. Another factor influencing attitudes is one's knowledge about the attitude object (e.g. fruit fly), which is positively related to the strength of an attitude. In our example, the peach grower would be very knowledgeable about the impact of fruit flies on her orchards and, therefore, would likely hold strong attitudes towards fruit fly and risk control strategies for the pest because of this invested knowledge. The strength of one's attitude towards an object, event or person(s) is often a good predictor of behaviour. However, as research has consistently demonstrated, an attitude (e.g. 'I believe that all peach growers should be vigilant in monitoring fruit flies on their property...') is not enough to explain behaviour (e.g. ' ... but if I report a fruit fly sighting, my property will exceed the threshold limit which has financial implications for my business'). Other psychological variables such as motivations and cognitive biases discussed in subsequent sections are also important to consider when understanding drivers of decision-making surrounding biosecurity risks (e.g. Bish and Michie 2010).

Attitudes can also guide perceptions related to a target event, object or person(s) and influence the type of information a person attends to (Kohler and Adams 1958). Perception, in the field of social psychology, is an active process of selection, organisation and interpretation of information. Existing attitudes help the brain to easily organise this information into something meaningful for the individual. The brain also engages in a process of selective attention, where it filters through the various stimuli we are exposed to, to determine what information is and is not important. Selective attention is a function of our pre-existing expectations derived from past experiences, our culture and our biology. Perception and attention together help humans navigate the profusion of information they experience and choose what internal stimuli (e.g. emotions) and external stimuli to allocate their attention towards. In the broader context of decision-making related to biosecurity risk, perceptions are likely to contribute significantly to acceptance and adoption of risk mitigation strategies. If our peach grower does not perceive a rise in fruit fly numbers as a likely or realistic threat due to zero pest prevalence in her region, she may perceive the risk and/or the recommended strategies as excessive, unnecessary or even irrelevant to her farming practices. This interpretation will depend on her individual psychology and risk profile.

\subsection{Risk attitudes}

As attitudes differ between people, the way in which people work through personal or work-related decisions involving risk and uncertainty also differs. Researchers define risk attitudes as the way in which a person makes risk-related choices or decisions using factors such as expected benefits, values, risk content and the risk context (Kahneman and Tversky 1979; Sarin and Weber 1993). This definition explains why people do not perceive a risky situation in the same way, why one person's perception of risk varies across different situations and why different people make divergent behavioural choices when faced with the same risk. The lens through which people may interpret their risk environment can be affected by inherent global attitudes, as well as pervasive specific attitudes regarding elements of risk. This includes an interpretation of how the issue might impact one's life on a social or economic level.

Weber et al. (2002) developed a scale for measuring risk perceptions and related behaviours, operationalising risk through five life domains: financial decisions, health and safety, recreational, ethical and social decisions. Their rationale was that if risk-taking is influenced by a combination of 
personal characteristics and the situational context, then a measure of risk-taking needed to consider these different content domains. Results from Weber and colleagues' research confirmed that people were not consistent in their riskrelated behaviour; rather, risk-taking was highly domain-specific. The research also showed that perceived benefits and risks of decision alternatives, however, influenced overall perception of risk in a given situation. Interestingly, Webster et al.'s research found a gender difference in risk-related behaviour, with women reporting greater risk aversion across all life domains compared to men, except social decisions.

The farm biosecurity context is a unique risk domain in that it can impact all aspects of a farmer's life due to the high personal, social, emotional and financial investment that a farmer has in his or her business. For example, a biosecurity response can influence:

- financial decisions (biosecurity compliance can be expensive)

- health and safety (stress caused by a biosecurity issue can negatively affect personal health)

- social environment (peer comparisons regarding biosecurity compliance can affect social relationships)

- ethical decisions (behaviours designed to control the spread of a disease has ethical implications for others in the industry) and, in some cases,

- biosecurity issues can affect risk-related decisions in the recreational domain (on-farm recreational activities or tourism opportunities may be deemed high-risk).

Farmers' multidimensional attitudes to risk, disease and security all play a role in the biosecurity response, whether it is a protective measure or whether the farmer is managing the fallout of an incursion. Research has consistently found that encouraging farmers to implement farm-level biosecurity is a challenge because they are unsure how emerging diseases will affect their individual properties and, as a result, may not immediately be motivated to invest in strategies that could benefit society but have little or no observable benefit to themselves (e.g. Gunn et al. 2008; Kristensen and Jakobsen 2011). However, from a psychological perspective, the influence or drive associated with non-financial incentives can arguably be equally as compelling.

\subsection{Social incentives, social norms and diffusion}

While not a focus of this paper, the economics associated with a biosecurity risk and consequent action is key to motivating individual action and should be integrated into any behaviour change initiative. Hennessy (2008) examined biosecurityrelated social incentives when protecting against pest invasion. Specifically, he looked at contexts where protective biosecurity action (e.g. regular pest inspections and cleaning) had a clear public good and where all in the region would benefit from pest absence. That is, 'non-acting firms' (i.e. people who did not carry out biosecurity practices) could not be excluded from the benefits of others' actions. Thus, it becomes a classic 'social loafing' (or 'free-rider') scenario of individual action and the complementary effect that others derive from this action. Typically, protective behaviour on one's farm means that the likelihood of entry from a biosecurity threat is minimised. This action not only reduces the risk of entry of an organism on individual farms, but it is also considered a public good whereby surrounding farms will also benefit from this individual's action. However, the protective action comes at a private cost, which co-beneficiaries will not have to bear. It is this discrepancy, or rather, disincentive that may deter individuals from engaging in shared protective biosecurity action and, instead, encourage them to free ride on the actions of others who make the decision to be proactive in biosecurity preparedness and who bear the cost.

Wang and Hennessy (2015) propose that this wrestle of public versus private benefit comprises a complex, multilevel set of interactions. Benefits are far-reaching (e.g. opening or regaining access to export markets), and it is impossible to 'exclude' potential beneficiaries. Further, individual benefits do not necessary correlate with individual efforts, thus forming a complex interaction of social and contextual issues. While this scenario is not economically optimal, it does bring with it a level of social currency and credibility. As Hennessy (2007 2008) points out in his discussion of probiosecurity incentives, not all incentives are material rewards. Rather, biosecurity-related decisions are likely influenced by perceptions of what others are doing and approval of one's actions from important others. This perception of referent regard or perceived judgement about one's behaviour comprises a social incentive, where engaging in socially desirable behaviours will elicit high regard from important others and provide a form of social currency. In the psychological sciences, the role of social influence on attitudes and behaviour is commonly examined within the realm of social norms.

Social norms are defined by Cialdini (2003) as having two perceptual references: (1) perception of what is commonly approved of (injunctive norm) and (2) perception of what is commonly done in a given situation (descriptive norm). Injunctive norms are very similar to subjective norms, which are often referred to in the literature as part of the popular and well validated model, theory of planned behaviour (TPB; Ajzen 1991). While this paper does not include an in-depth discussion of the TPB, it is important to acknowledge that while the TPB may have its limitations, it is a useful tool in predicting intentions to engage in behaviours as it incorporates the potential of normative social influences. Hu et al. (2006) examined farmers' use of new technology in predicting climate and weather forecasts using the TPB. Their premise was that the accuracy of forecasting and public understanding of 
climate variability has dramatically and continuously improved in recent years; yet, the way in which farmers use the information when making farming decisions has remained relatively unchanged. Hu and colleagues argued that farmers' beliefs regarding who else was using the technology and the perceived value of these others' views (normative pressure) would still be a dominant influence on their own forecast attitudes and intentions to use the technology.

Two key results from Hu et al.'s study were found to be relevant to the biosecurity context. They first demonstrated that farmers' scores on perceived utility of forecasting and the perceived value of forecasts were relatively low amongst this sample, which likely contributed to poor use of the technology. Secondly, the source from which the forecast information originated was key to influencing intentions, as ambiguous identity of forecasters influenced perceptions of trust in the accuracy of information provided, as well as the development of skills on how to best use the forecast information. In applying this to the biosecurity context, it would seem that in order to increase compliance: (a) there must be evidence or at least the perception that the recommended biosecurity responses are useful and effective, (b) the recommendations/call to action must come from a trusted and credible source and (c) a perception exists that others in the referent peer group are behaving in the same way (i.e. social comparison is important).

Gunn et al. (2008) also utilised the TPB and conducted a key study in relation to British farmers' biosecurity attitudes, examining the role of social and normative attitudes in limiting biosecurity improvements. The researchers compared perceived constraints to biosecurity amongst farmers and auxiliary personnel such as veterinary practitioners and industry representatives. Interestingly, the researchers found that the different groups had very clear-but different-ideas about biosecurity for well-known pests and diseases. In particular, the groups differed in their expectations of assigning responsibility for biosecurity and perceptions of associated attitudes. Farmers in this study believed that while they were ultimately responsible for biosecurity management on-farm, other stakeholders such as industry and government should make a greater contribution towards biosecurity. Farmers saw this as a major constraint in improving biosecurity arrangements in Great Britain. In contrast, when veterinarians were asked about major constraints to biosecurity, they cited their clients' (i.e. farmers') willingness or financial ability to engage in biosecurity as the major issue. However, veterinary practitioners also added that there was a need to better demonstrate evidence that recommended biosecurity activities were effective and/or that economic benefits could be derived from improved biosecurity. Crucially, farmers appeared to perceive little efficacy of on-farm biosecurity activities in the absence of action by others.

The influence of social norms on decision-making and behaviour has long been recognised in the context of farming, from early work about normative on-farm gender roles (e.g. discussed by Alesina et al. 2013) to the social and comparative influences of relevant peers (e.g. neighbours) in the adoption of innovative farming practices (e.g. Wilkening 1950). Norms are an inherent part of social systems and structures, such as farming groups or communities. Norms are typically developed through a process of socialisation within a given social context and can engender underlying farming 'intuition' or distinct farming practices, habits and standards within a social group (e.g. family, company, industry). Norms can influence farmer behaviours, specifically, through the process of diffusion. Diffusion is conceptualised as a process of social change, whereby innovation is communicated over time through social channels within a social structure or system (diffusion of innovation theory; Rogers 2004; Valente and Rogers 1995). Early research in the agricultural context found the process of diffusion exerted normative pressure on farmers (of comparable socioeconomic standing) to adopt innovative farming practices championed by early adopters in the neighbourhood. The rationale was that evidence of implementation and success of innovative practices was the most effective way to change farmers' behaviours (Young and Coleman 1959).

While the foundational research on diffusion was conducted over 60 years ago, the findings remain relevant and diffusion of innovation theory is still a widely used framework for understanding adoption of technologies in the global agricultural sector (e.g. see reviews by Simin and Janković 2014; Toborn 2011). Peshin et al. (2009) further discuss that diffusion of innovation can be used in the context of understanding uptake for integrated pest management innovation. However, they acknowledged that the theory does not account for practical issues limiting innovation adoption, such as constrained financial resources. This early research into farmer norms highlights the role that social norms play in guiding what is socially acceptable and the importance of 'what everyone else is doing'. These normative influences are therefore important in understanding initial attitudinal drivers for the acceptance of biosecurity management recommendations, and the subsequent motivation to adopt or reject biosecurity practices within a relevant social group (i.e. farmer groups).

\section{Motivation and adherence}

As explained in Section 1, people typically attend more closely to threat protection information that is relevant to their present context and they will act upon information which serves their own beliefs, desires, goals and capabilities (Kohler and Adams 1958). Motivation is defined as an internal process that initiates, guides and maintains behaviour towards a goal. In simple terms, motivation is the reason people act a certain way and why they are directed towards a 
particular behaviour. Motivation can be discussed in terms of values (e.g. environmental values, business/personal values; de Groot and Steg 2010) and orientations (e.g. extrinsic, intrinsic, ego, task; Deci and Ryan 1987; Heyman and Dweck 1992; Nicholls 1984). For example, when considering decisions related to biosecurity risk management, farmers may be motivated by various things, such as their beliefs in shared responsibility (i.e. values), the monetary gains or losses involved in carrying out risk mitigation activities (i.e. extrinsic motivation) or their desire to run the best farm facility possible (i.e. task orientation). An understanding of what motivates farmers can then assist administrators, researchers and communicators in developing better ways to communicate biosecurity risk, recommended risk mitigation strategies and the vulnerability to/or severity of potential biosecurity risks.

In a study of farmer motivation to improve mastitis management in dairy cows, Valeeva et al. (2007) explored the different motivating factors in dairy farmers' decisions to better manage mastitis and the utility of financial incentives as a motivational tool. Results showed that farmers were motivated primarily by intrinsic and task-oriented factors central to individual farm performance; the farmer sample ranked job satisfaction and the severity of the mastitis problem as most motivating. Third in this ranking process were economic losses, which dairy farmers found equally as motivating as concern for animal health and welfare in managing mastitis. The least important motivational factors were individual recognition and product image, both of which are considered external and ego-oriented factors. Similarly, Reimer et al. (2012) examined how a group of US farmers made conservation decisions on their farm. Once again, farmers who were motivated by performance of the farm and broader, off-farm environmental benefits were more likely to adopt conservation practices. In contrast, farmers who were focused on the farm as a business were less likely to adopt environmental practices because of their concern about overall profitability. This study, in particular, highlights a parallel with the adoption of biosecurity practices. That is, farmers can choose to engage in preventative and innovative biosecurity measures; however, individual growers will be influenced by their existing values and beliefs and be driven by factors that motivate them towards action. It is these motivational drivers that are poorly understood in the context of behaviour adoption and change in agricultural biosecurity practices.

Motivating farmers to engage in, and comply with, biosecurity management practices is only part of the process - facilitating and encouraging farmers to adhere to their chosen risk management practices is a further challenge. Once the initial motivation for adopting a new practice on the farm wanes, it is important to understand what factors will motivate an individual to persist with risk management strategies that may not have immediately observable or quantifiable effects. In contrast to compliance, which means the extent to which one's behaviour coincides with the recommended response, adherence typically describes the process of complying with a recommended response or action over a sustained period of time to achieve the end goal (Dishman 1988; Hermon and Hazler 1999). Adherence can also play a role in the context of prescriptive norms surrounding biosecurity risk management activities, where motivation to adhere to biosecurity norms shared by a society or group may be influenced by real or perceived 'sanctions' to non-compliant behaviour (Thøgersen 2003). There are two types of prescriptive norms, social and personal, that can help to explain motivation. Adherence to personal norms may be influenced by feelings of social pressure to adhere to normative behaviour 'for the good of the group' and adherence to personal norms is typically because the individual feels the behaviour is the 'moral' thing to do.

Understanding the various motivational triggers for farmers can help to target incentives to encourage and maintain engagement in more pro-biosecurity behaviours, and incentivise the initial reporting of biosecurity concerns such as suspicious plants or animals. Palmer et al. (2009) investigated the motives and behaviours driving farmers' decisions to report unusual symptoms in their livestock, after an Australian report cited a decline in official reporting to livestock illnesses and death. The results from Palmer and colleagues' study showed that seven factors were influential in reporting behaviour amongst livestock farmers, with a mixture of attitudinal and situational variables. These included perceived approachability of the government-affiliated farm advisor, distance to and adequacy of the reporting site (i.e. in this study, it was the veterinarian's clinic), existing biosecurity practices on-farm, perceived risk of disease outbreak, perceived personal control, self-efficacy and trust in others (e.g. neighbours, other farmers and extension personnel). Therefore, while situational factors are important contributors to farmers' reporting behaviour, attitudinal factors were also influential drivers.

Much of the literature related to motivation in farmer decision-making has utilised the protection motivation model of threat appraisal and risk perception, which also utilises variables such as self-efficacy and perceived control. This perspective relies on the conceptualisation of fear as an emotional motivational state that protects one against danger (Rogers 1983). Historically, emotions have also been cited as having a close relationship with muscular activity, thus the suggestion that fear causes an emotional disturbance within the body which triggers muscular activity that protects the organism from the dangerous stimulus (e.g. fight or flight response). In the present biosecurity context, this description would suggest that farmers experience an emotional, possibly fearful, reaction to a biosecurity threat, and the real or potential consequences of this threat. This perception will motivate the individual to protect themselves, their family and their 
property by either fighting the threat through modified behaviours or fleeing the threat via threat denial and avoidance.

\subsection{Protection motivation}

The focus of protection motivation theory is the motivational aspect of threat perception and the associated fear. The emotion of fear is a relevant inclusion in a discussion of what motivates farmer risk decision-making. Fear has the potential to facilitate attitude and behaviour change and can drive an individual to learn adaptive responses to cues or threatening stimuli (Rogers 1983). As Rogers (1975, 1983) describes in his theory of protection motivation, the three most important variables in a fear appeal are as follows: (1) the magnitude of harm in a depicted event, (2) the conditional probability that the event will occur if no protective attempt is made and (3) the belief in the effectiveness (efficacy) of the suggested coping response. Each of these processes is said to independently appraise information about the threat severity, probability and efficacy of responses specific to an event (Rogers and Mewborn 1976) and arouse a 'protection motivation' response to mediate the effects of the fear appeal. Rogers (1983) later revised his model of protection motivation by including broader antecedent sources of information (e.g. personal factors), as well as greater detail on cognitive processes of threat appraisal (i.e. threat severity and vulnerability, intrinsic vs. extrinsic rewards), coping appraisal (i.e. response efficacy, self-efficacy, response costs) and which behaviours would be considered adaptive or maladaptive coping responses.

The key inclusion in Rogers' revised protection motivation model is that of self-efficacy, which is the (positive or negative) belief in one's ability to carry out a behaviour (Bandura 1977). Bandura argues that self-efficacy pervades all psychological processes of change by influencing whether coping behaviours will be initiated, whether they are adaptive or maladaptive, and the intensity and duration of effort expended to achieve the target behaviour(s). Research has shown that farmer self-efficacy can influence ability to organise and execute behaviours to achieve agricultural performance and plays a significant role in decisions to change behaviour (Roy Dutta 2009; Wu and Mweemba 2009). Rogers (1983) argues that while high self-efficacy can help an individual to engage in adaptive protection behaviours, when people feel as though they have an inability to protect themselves (i.e. low perceived self-efficacy), they likely experience feelings of helplessness and lack of control within a situation. Low self-efficacy may then motivate an individual to seek out some sense of perceived control, which Rogers suggests could be achieved by purposefully choosing to engage in behaviours that will bring about a threatening event. In a biosecurity context, this can have negative consequences not only for the individual but also for associated parties, such as neighbouring farms, contract workers, community members and, potentially, the whole industry. Therefore, examining self-efficacy in the biosecurity context is highly relevant and could provide valuable information regarding the drivers of risk decision-making amongst farmers.

Perceived costs associated with a biosecurity response are likely to be particularly salient for the farming community, because of the small margins that most farmers typically work with and the increased labour or efficiency costs associated with implementing and maintaining a recommended biosecurity response. For example, a key biosecurity response designed to reduce the risk of fruit fly choosing a potential host site is to clear away fallen and/or rotting fruit beneath trees in the orchard (orchard hygiene). However, in order to do this, the farmer must weigh up costs associated with the increased time taken to carry out that activity, the increased labour that might be involved, the potential cost of new equipment and the disposal of the collected waste fruit. This is just one example in a suite of many such issues related to implementing recommended biosecurity protocols on-farm. If a farmer does not have the ability to take on some of the more cost-intensive biosecurity activities, this realisation may come at a great emotional cost, such as increased stress and anxiety.

\section{Emotion, stress and attachment}

The depth and breadth of emotion research in psychology has established that people make different decisions based on their emotional state, as well as the emotions elicited by a particular situation. Emotions are defined as a complex integration of psychological and physiological experiences in response to a stimulus. Emotions influence human behaviour and can guide perceptions of risk (Mankad 2012; Myers 2004). In particular, emotions associated with existing cognitive beliefs and attitudes are likely to play a central role in decision-making specific to risk management. It is interesting to observe that often, it is the 'unknown' associated with a threat that may elicit the most negative emotion and increase levels of stress. For example, dealing with a biosecurity incursion on one's property may initially produce intense emotion and stress. However, over time one becomes habituated to the threat and will likely develop some coping mechanisms to help alleviate the mental distress. This can be facilitated by greater knowledge about the threat itself, about the emergency response process, and about the future. In contrast, those individuals who have yet to experience the biosecurity event, but are within the broader contamination zone, may experience heightened stress due to anxiety, unfamiliarity and helplessness regarding susceptibility to the threat.

In the environmental science literature, researchers have found that emotions also play a role in place attachment, which is a positive connection or bond between a person 
and a place (Williams and Vaske 2003; Gosling and Williams 2010). Results from this research show that place attachment significantly influences environmentally relevant behaviour, including a greater willingness to engage in vegetation protection behaviours amongst farmers, which increased in line with their perceived connectedness to nature (e.g. Gosling and Williams 2010; Stedman 2002; Vaske and Kobrin 2001). The issue of place attachment is relevant to decision-making in the biosecurity context because farmers are likely have an attachment to their farm, the land that they work and perhaps even the broader community that they are a part of; this attachment may be even stronger if a family has been on the same land for generations. In the context of risk management, it could be argued that farmers and/or farm workers responsible for decision-making may make more 'protective' decisions about biosecurity management if they have higher place attachment, than if they did not. This may also be the case for those individuals who gain a strong sense of identity or selfworth from the farm and farming practices. Schultz (2000) argues that the more someone cognitively and emotionally incorporates an object into their sense of self the more emotional value that object has.

As Norris et al. (2008) note, place attachment may also be relevant for disaster recovery. During a disaster event, such as a biosecurity incursion, people can be displaced from the homes and neighbourhoods from which they draw comfort and where they are deeply connected. The role of place attachment has not typically been examined in the biosecurity domain, as either a precursor to protective decision-making or as an emotional factor in the event of a biosecurity emergency. However, we can learn from other domains that the impact of displacement after an emotional event can be significant and could go so far as to impair resilience in some instances (Lane and Robinson 2009; Brown and Westaway 2011). Other researchers argue that place attachment could also facilitate resilience and increase the likelihood that a community could rebuild after a disaster (Manzo and Perkins 2006; Miles 2015). While inconclusive, the research certainly suggests that place attachment could be an important factor to consider when exploring risk decisionmaking (Leith and Vanclay 2016). As Norris et al. (2008) describe, disasters happen to entire communities and members within the community are exposed together and are likely to benefit from recovering together.

The issue of disaster is not separate from the issue of stress. People experience high levels of stress when dealing with a crisis due to limited resources, adaptation to changing circumstances and uncertainty. Stress is defined by the Australian Psychological Society (2002) as a feeling of being overloaded and can manifest in symptoms such as headaches, sleep disturbance, anxiety, depression, fatigue and low self-esteem. On a daily basis, farmers are required to make crucial decisions under conditions of stress and, sometimes, in the face of highly emotional circumstances. While acute stress can be a motivating experience for some (e.g. 'working well under pressure'), chronic stress such as that caused by a disaster can be harmful to well-being if it is perceived as being excessive and affecting one's ability to carry on normal life. In the biosecurity literature, a disease or pest outbreak has been shown to significantly impact emotional stress levels. Hernández-Jover et al. (2012) evaluated pig farmers' perceptions about the H1N1/09 influenza virus, which was poorly labelled 'swine flu' and resulted in public misconceptions about how the disease was transmitted. Results showed that the outbreak had significant financial impact on pig producers and there was an increased adoption of biosecurity practices, particularly for larger herds. Importantly, the study reported that in addition to financial stress, $27 \%$ of farmers were feeling emotionally distressed and almost $40 \%$ were stressed about the health of their pigs.

Another study, conducted by Taylor et al. (2008), examined the social impacts of the equine influenza (EI) outbreak in Australia, which occurred during spring, the busiest time of the year for Australian horse sports. The EI outbreak caused significant disruption to all horse sporting events and had significant social and industry impacts (Hoare 2011). Taylor and colleagues reported that $34 \%$ of horse owners reported high levels of psychological distress, compared to $12 \%$ in the general Australian population, and their analyses showed that younger people were more likely to report high psychological distress. In particular, psychological stress was twice as likely to be high amongst those whose primary source of income was horse-related. Taylor et al. (2008) found that much of this stress was also due to movement restrictions for horses within the different biosecurity restriction zones (red - high-risk zone, amberbuffer zone), with movement permits difficult to obtain and even trips to and from the veterinarian were only approved for emergency reasons; those situated in the 'white zone' (unaffected by the EI crisis) were less likely to report psychological distress. Interestingly, although the prevalence of psychological distress was high in the specific EI zones, elevated psychological distress was prevalent amongst horse owners nationally, highlighting the far-reaching effects of severe biosecurity incursions beyond the immediate affected zones.

A stressful farming environment, therefore, can have important implications for farmers' quality of life in other areas, such as physical health and emotional well-being. Emotions can be significantly influential in determining a coping response in the context of a stressful event or even perceived threat. Relatedly, emotions also play an important role in the effectiveness of communicating the severity and vulnerability of a threat to those likely to be affected, as well as advocating for particular response activities. Psychological research has demonstrated that the impact of persuasive messages can depend upon the emotional state of the receiver and the framing of the message (e.g. Ganzach and Karsahi 1995; Mankad 2012; McCusker and Carnevale 1995). This leads to the topic 
of cognitive bias and how it may influence farmer risk decision-making.

\section{Cognitive bias}

When people are making everyday judgements and decisions, it is often assumed that the cognitive process taking place is objective, logical and comprehensive in the way that information is decoded and recoded. However, humans are far from the unbiased decision makers that we may strive to be and we are all subject to cognitive biases in the way we understand information and ultimately make decisions. A cognitive bias is an error in decision-making, whereby one's judgement is influenced by existing patterns of beliefs and perceptions. Typically, cognitive biases come about because of our mental reliance on heuristics, which are cognitive 'shortcuts' that simplify the complex, vast and sometimes incomplete information we receive through our sensory system, so that we can make decisions efficiently. However, the simplification process of heuristics means that we can introduce errors into our judgements. Thus, even our 'objective' judgements and 'rational' decisions are influenced by many inherent biases that we may not even know exist within our consciousness, producing errors in our judgement and decision-making.

Cognitive bias can also be conceptualised as a form of subjective logic and it is this that makes it most relevant to the farm biosecurity context. Farmers, especially experienced farmers, typically have their own 'logic' that guides their farming practices. The logic is based on past experiences, as well as an understanding of the crops they are growing or animals they are raising. For more inexperienced farmers, important others were used as a reference for their own behaviour. Farmers also often rely on 'rules of thumb' which can be accepted industry-relevant activities or simply relevant to individual farming protocols based on an understanding of the environmental context. Research supports the existence of such biases, suggesting that farmers base most of their decisions on 'gut instinct' and intuition, rather than any formal education (e.g. Öhlmér et al. 1998; Hoe and Ruegg 2006). These biases can also help to create farmer or industry norms discussed in Section 2.2 and contribute to the perception and assessment of risk (Section 2.1). Therefore, while farming practices have improved in leaps and bounds from a technological and professional perspective, inherent biases that exist and those that may have existed for generations can exert important influences on biosecurity attitudes, implementation beliefs and management behaviour. Biases can also impact how biosecurity-relevant communications are interpreted, as well as the ensuing decision-making process.

The framing of messages is an important factor in the context of biases, particularly because framing has important implications for how biosecurity risk communication might be delivered and perceived. In psychology, the framing effect is an example of a cognitive bias where people react to a message in different ways depending on how the message is presented-or framed. Grounding research by Tversky and Kahneman (1981) on the area of loss and gain messaging found that typically, people tend to avoid risk when a message is framed positively but are more likely to seek risks when a message is framed negatively. Thus, farmers may be more likely to take on biosecurity information and behaviour change on-farm if the communication is framed in a positive way (e.g. positive: fruit fly numbers will decrease by $200 \%$ if you remove rotten fruit vs. negative: fruit fly numbers will increase by $400 \%$ if you do not remove fallen fruit).

\subsection{Cognitive dissonance}

An example of another type of bias that is relevant to behaviour change in the farming context is cognitive dissonance. Cognitive dissonance is when an individual experiences psychological stress because they hold two or more conflicting beliefs (Festinger 1961). To relate this definition to the farm biosecurity context, take the example of our peach grower, who is likely to have clear views about a particular wellknown pest (e.g. Queensland fruit fly). She has clear ideas about how it might have arrived on-farm and/or the movement patterns of the pest. These existing cognitive beliefs will then influence the interpretation of information communication and drive biosecurity management and/or eradication behaviour. However, this bias to new information also means that if the grower is given updated information that is in direct conflict with what she already believes to be true about the pest, she is faced with a mental discomfort originating from this discrepancy, a phenomenon referred to as dissonance. The grower must decide whether to: (a) ignore the new information being provided in favour of what she already believes to be true and continue to behave in a way that is aligned with her pre-existing cognitions about the pest; or (b) she must adjust her existing beliefs in light of the new information in order to 'comfortably' change her behaviour and act in a way that is contradictory to her original beliefs. Essentially, humans do not deal well with holding two or more beliefs that are in direct conflict with each other and look to reduce this psychological stress by pursuing internal consistency in their beliefs, values and behaviours.

A key application for the cognitive dissonance effect in the farm biosecurity domain is to understand that people will actively avoid situations that do not align with their existing beliefs. For example, our peach grower may observe evidence that her neighbours are installing fruit fly traps and picking up fallen waste fruit from underneath trees in an effort to be more biosecurity conscious due to the increasing threat of fruit fly. However, our peach grower does not believe fruit fly to be a credible threat. Therefore, 
in order to preserve the accuracy of her beliefs, she will likely not attend community forums discussing the threat of fruit fly, ignore updated information about fruit fly and dismiss the neighbour's proactive behaviour as unnecessary. Therefore, if biosecurity administrators or extension personnel are trying to convey a message about on-farm biosecurity, the best way to maximise message exposure - particularly to reach those individuals who are actively disinterested in changing their attitudes - is to deliver the information in a non-threatening way, in a trusted environment and in a way that appeals to familiar concepts. This approach will ensure that the message receiver does not have to deviate too far from what is mentally comfortable and is less threatened by new information. Further, the message of greater biosecurity engagement is likely to be valued more if it is framed in such a way that the grower perceives the outcome as highly desirable and the negative aspects of involvement are minimised.

\section{Socio-contextual factors}

The final discussion is related to the more precursory influences on decision-making around biosecurity risk, which are socio-contextual and demographic factors. This category includes factors such as socioeconomic status, education, gender, age/stage of life, quality of life priorities and business type/size. Research shows that farmers' willingness to accept new information or engage in actions related to a biosecurity threat may be influenced by the life stage of the farmer and their needs and goals at that point in time.

Garforth (2010) found that while commercial growers were primarily interested in a business approach, independent/small farmers and enthusiast/hobby growers whose main income was not derived from farming scored highly on 'quality of life' as a driver for their on-farm decisions and behaviour. Other researchers have demonstrated that larger producers tend to have better biosecurity and more 'professional' setups, likely because they have more liquid assets available to contribute to protecting the business from biosecurity threats and because they have more to lose (i.e. they have greater risk at stake; Hoe and Ruegg 2006; Hernández-Jover et al. 2012). Therefore, quality of life priorities and 'stage of life' factors (e.g. young entrepreneurial farmer vs. semi-retired farmer) can significantly impact decisions relating to on-farm biosecurity. Further, it is not only growers who are significantly impacted by, and responsible for, biosecurity engagement. This responsibility extends from national industry bodies to the casual backyard gardener, all of whom must consider changing habits and behaviours in response to an increased biosecurity risk or threat, depending on their proximity to the threat.

Socio-contextual factors can also significantly impact adherence to on-farm biosecurity activities. While much of the empirical psychology literature on behavioural adherence comes from the health and sport/exercise psychology domains, adherence is a key concept in the study of biosecurity engagement. Schemann et al. (2011) examined the concept of adherence in an evaluation of biosecurity compliance amongst horse owners 1 year after the 2007 EI outbreak, when biosecurity compliance was presumably at its peak. Results showed that $50 \%$ reported high biosecurity compliance 1 year post-EI, and $30 \%$ reported low compliance. Key qualitative responses justifying changed behaviours amongst this sample were that they would shift their behaviour and follow practices only during an outbreak and that some practices were unnecessary, ineffective or impractical (e.g. avoiding contact with other horses). Overall, Schemann et al. found that younger people were less likely to comply with recommended practices, which is consistent with past research on protective behaviours, along with people with two or more dependents. Perceptions of real or anticipated financial impacts, older people and those with commercial interests were more likely to report higher biosecurity compliance. Therefore, this study and others highlight the important of socio-contextual factors, such as demographics and lifestyle differences, on adherence to biosecurity measures on-farm.

\section{Summary and implications for a social-psychological model of biosecurity engagement behaviour}

The purpose of this review is to present key psychological factors that can help to understand why farmers make the decisions they do when dealing with pest management issues, particularly when potential risks are clear to others and economic benefits or production efficiencies are seemingly at stake (Garforth 2010). From the concepts discussed here, it is clear that understanding the cognitive reasoning processes driving decisions around biosecurity risk are key to understanding farmer behaviour and the best ways to approach behaviour change. Furthermore, farmers do not make decisions in the same way as each other; each farmer will make decisions about biosecurity risk in a nuanced way influenced by unique social, psychological and contextual factors. Most research on biosecurity attitudes clearly demonstrate that farmers' views are at odds, specifically, the moral wrestle between collective/societal benefits of greater biosecurity engagement and investment versus individual/private costs of biosecurity implementation. Early social research in the area of biosecurity suggests that engagement in biosecurity activity seemingly comes down to perceptions of economic viability (Gunn et al. 2008; Heffernan et al. 2008; Kristensen and Jakobsen 2011). If that is indeed the case, then how do administrators and advocates appeal to a farmer's motivation to not only protect themselves and their crops from a biosecurity threat but also engage them in a shared approach that protects 
their peers and the wider industry from the consequences of a biosecurity incursion?

\subsection{A hypothesised model of farmer risk decision-making}

After reviewing the biosecurity literature within social science, a simple model for understanding farmer decisionmaking in the context of biosecurity is proposed (Fig. 2). The first stage of factors influencing a biosecurity response will be socio-contextual factors which are inherent in any decision response; these are factors discussed in Section 6, but are interwoven throughout. The second stage involves key psychosocial concepts that are nuanced considerations in the context of a unique biosecurity threat or proposed response (presented in Sections 2-5). Rogers' (1983) protection motivation theory is incorporated as a part of this proposed model; his model states that behavioural intentions are positively influenced by: (1) perceived threat severity, (2) perceived personal vulnerability to the threat, (3) self-efficacy in carrying out the recommended response(s) and (4) belief that the recommended response(s) are effective in avoiding the threat. Protection motivation theory also assumes a negative linear relationship when: (1) there are desirable reinforcements for engaging in a maladaptive response and (2) the costs (e.g. time, money) associated with the recommended response(s) are too great. The difference with this proposed model is that there are no assumptions made about the linearity of the relationship between variables linked with protection motivation theory; thus, this model is classed as exploratory because of the relatively unknown influences in a biosecurity context. From a risk communication standpoint, the 'vividness' of information received from a source (i.e. the detail and specificity of information), as well as source credibility, is argued to positively influence perceptions of threat severity. Therefore, the concept of framing effects has been incorporated into the second step of this model also.

The role of perceived costs, in Fig. 2, has been embedded as a potential mediator in the subsequent relationship between biosecurity engagement intentions and ultimate biosecurity engagement behaviour. While protection motivation research consistently shows that perception of costs associated with a protective response are influential in predicting intentions (discussed in Section 3.1), the current model proposes that perceived costs will also be important in understanding the extrapolation from intention to engage in biosecurity to onfarm action (Fig. 2).

An analysis of social norms in this model is important because it provides researchers with an opportunity to understand how and why biosecurity compliance is lacking in some industries and regions, and how to improve uptake or 'buy-in'. The key message from a discussion of social norms is that farmers may be more likely to adopt biosecurity strategies or technologies if there exists a perception that 'everyone else is doing it' and there are perceived social consequences (e.g. identified as 'the weakest link') if the individual farmer does not comply. This is considered to be a strong predictor of biosecurity engagement in the present model.

\section{Conclusion}

While biosecurity is perceived as an important part of on-farm management and is advocated as a norm for all crop and animal based industries, commitment and full engagement in such protective or preventative action is not the norm (e.g. Kristensen and Jakobsen 2011). In an increasingly small world where plants, materials and humans move from one area to another and introduce an unprecedented level of risk, the importance and relevance of biosecurity becomes crucial in protecting national food production industries. Along with that comes an increased awareness spurred on by greater education and communication of risk, as well as greater advances in biosecurity-relevant technologies. Policy on biosecurity around the world currently advocates the notion of 'shared responsibility', where all citizens play a role in minimising and controlling biosecurity threats to plants, animals and humans. Yet, most policy documents rarely consider the human component of biosecurity action, such as motivation to engage in recommended practices and adherence to protective behaviours. That is, individuals have their own unique psychological profile and while social factors can influence contextual decision-making, underlying psychological traits will inherently influences decision-making and interpretation of risk.
Fig. 2 Exploratory psychosocial model of factors influencing farmer decision-making for a biosecurity response, based on a review of available psychosocial literature
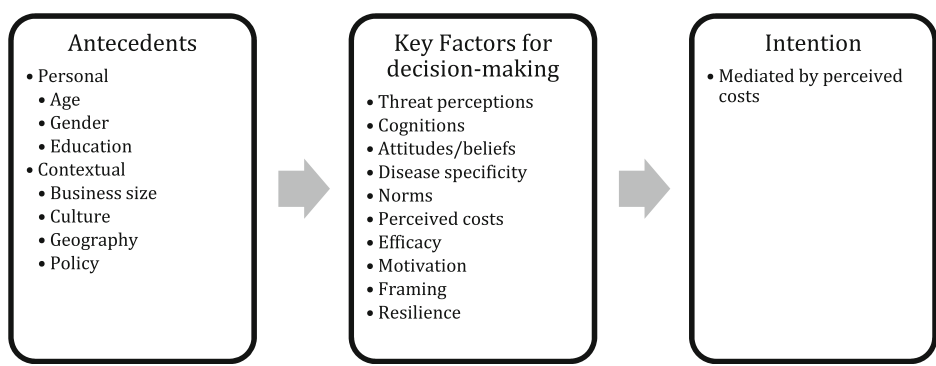

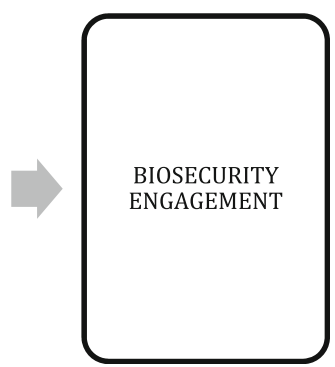


What past biosecurity incursions are typically highlighting is that a community-wide biosecurity response is less about an expert-led scientific eradication response and more about social and psychological factors that contribute to an interpretation of risk and consequent drive towards action. This suggests that framing of biosecurity emergencies in policy literature should maintain the idea of shared responsibility but also clearly communicate the role of risk within its political, institutional and psychological contexts (Mankad 2012; Robinson et al. 2005). Greater research on institutional factors such as coordinated identification of risks, research on effective communication strategies and the provision of feedback related to risk management compliance could shed light on drivers that encourage farmers to adopt improved biosecurity practices on their properties (Monroe 2003), particularly during non-emergency, day-to-day operations. In making biosecurity-driven changes on-farm, farmers can adequately prepare and protect against pests and diseases, with the hope that an outbreak does not occur or that it can be effectively managed if it does occur. In doing so, gains can be expected in savings from improved operational management, pest management, reduced production losses and improved market access.

Acknowledgments The author would like to thank Cathy Robinson and Carol Farbotko for reviewing earlier versions of this manuscript, which benefited from their expertise.

\section{References}

Abdalla A, Millist N, Buetre B, Bowen B (2012) Benefit-cost analysis of the National Fruit Fly Strategy Action Plan Report. Australian Bureau of Agricultural and Resource Economics and Sciences (ABARES)

Ajzen I (1991) The theory of planned behavior. Organ Behav Hum Decis Process 179-211. doi: 10.1016/0749-5978(91)90020-T

Alesina A, Giuliano P, Nunn N (2013) On the origins of gender roles: women and the plough. Q J Econ 128:469-530. doi:10.1093/qje/ qjt005

Australian Psychological Society (2002) Understanding and managing stress. Aust Psychol Soc Ltd 2

Bandura A (1977) Self-efficacy: toward a unifying theory of behavioural change. Psychol Rev 84:191-215

Beale R, Fairbrother J, Inglis A, Trebeck D (2008) The independent review of Australia's quarantine and biosecurity arrangements report to the Australian Government.

Bish A, Michie S (2010) Demographic and attitudinal determinants of protective behaviours during a pandemic: a review. Br J Health Psychol 15:797-824. doi:10.1348/135910710X485826

Brown K, Westaway E (2011) Agency, capacity, and resilience to environmental change: lessons from human development, well-being, and disasters. Annu Rev Environ Resour 36:321-342. doi:10. 1146/annurev-environ-052610-092905

Buetre B, Wicks S, Kruger H et al (2013) Potential socio-economic impacts of an outbreak of foot-and-mouth disease in Australia. Australian Bureau of Agricultural and Resource Economics and Sciences, Research Report 13.11. Canberra, ACT
Cialdini RB (2003) Crafting normative messages to protect the environment. Curr Dir Psychol Sci 12:105-109. doi:10.1111/1467-8721. 01242

de Groot JIM, Steg L (2010) Relationships between value orientations, self-determined motivational types and pro-environmental behavioural intentions. J Environ Psychol 30:368-378. doi:10.1016/j. jenvp.2010.04.002

Deci EL, Ryan RM (1987) The support of autonomy and the control of behavior. J Pers Soc Psychol 53:1024-1037

Department for Environment Food \& Rural Affairs (2014) Protecting plant health. A Plant Biosecurity Strategy for Great Britain, UK

Department of Primary Industries (2013) New South Wales Biosecurity Strategy 2013-2021. Sydney

Dishman RK (1988) Exercise adherence research: future directions. Am J Health Promot 3:52-56

Enticott G, Vanclay F (2011) Scripts, animal health and biosecurity: the moral accountability of farmers' talk about animal health risks. Health Risk Soc 13:293-309. doi:10.1080/13698575.2011.575456

Festinger L (1961) The psychological effects of insufficient rewards. Am Psychol 16:1-11

Food and Agriculture Organization of the United Nations (2009) Strategic framework 2010-2019. United Nations, Rome

Food and Agriculture Organization of the United Nations (2013) Aquastat. http://www.fao.org/nr/water/aquastat/water_use/index. stm

Ganzach Y, Karsahi N (1995) Message framing and buying behavior: a field experiment. J Bus Res 32:11-17

Garforth CJ (2010) Motivating farmers: insights from social psychology. $60-67$

Gosling E, Williams KJH (2010) Connectedness to nature, place attachment and conservation behaviour: testing connectedness theory among farmers. J Environ Psychol 30:298-304. doi:10.1016/j. jenvp.2010.01.005

Gunn GJ, Heffernan C, Hall M et al (2008) Measuring and comparing constraints to improved biosecurity amongst GB farmers, veterinarians and the auxiliary industries. Prev Vet Med 84:310-23. doi:10. 1016/j.prevetmed.2007.12.003

Heffernan C, Nielsen L, Thomson K, Gunn G (2008) An exploration of the drivers to bio-security collective action among a sample of UK cattle and sheep farmers. Prev Vet Med 87:358-72. doi:10.1016/j. prevetmed.2008.05.007

Hennessy DA (2007) Biosecurity and spread of an infectious animal disease. Am J Agric Econ 89:1226-1231. doi:10.1111/j.14678276.2007.01088.x

Hennessy DA (2008) Biosecurity incentives, network effects, and entry of a rapidly spreading pest. Ecol Econ 68:230-239. doi:10.1016/j. ecolecon.2008.02.023

Hermon DA, Hazler RJ (1999) Adherence to a wellness model and perceptions of psychological well-being. J Couns Dev 77:339-343. doi:10.1002/j.1556-6676.1999.tb02457.x

Hernández-Jover M, Taylor M, Holyoake P, Dhand N (2012) Pig producers' perceptions of the Influenza Pandemic H1N1/09 outbreak and its effect on their biosecurity practices in Australia. Prev Vet Med 106:284-94. doi:10.1016/j.prevetmed.2012.03.008

Heyman GD, Dweck CS (1992) Achievement goals and intrinsic motivation: their relation and their role in adaptive motivation. Motiv Emot 16:231-247

Heymann DL (2005) Social, behavioural and environmental factors and their impact on infectious disease outbreaks. J Public Health Policy 26:133-139. doi:10.1057/palgrave.jphp.3200004

Hoare R (2011) Overview of the industry and social impacts of the 2007 Australian equine influenza outbreak. Aust Vet J 89(Suppl 1):14750. doi:10.1111/j.1751-0813.2011.00770.x

Hoe FGH, Ruegg PL (2006) Opinions and practices of Wisconsin dairy producers about biosecurity and animal well-being. J Dairy Sci 89: 2297-308. doi:10.3168/jds.S0022-0302(06)72301-3 
Hogg MA, Vaughan GM (2005) Social psychology, 4th edn. Prentice Hall

Hu Q, Zillig LMP, Lynne GD et al (2006) Understanding farmer's forecast use from their beliefs, values, social norms, and perceived obstacles. J Appl Meteorol Climatol 45:1190-1201. doi:10.1175/ JAM2414.1

Kahneman D, Tversky A (1979) Prospect theory: an analysis of decision under risk. Econometrica 47:263-292

Kohler W, Adams PA (1958) Perception and attention. Am J Psychol 71: 489-503

Kristensen E, Jakobsen EB (2011) Danish dairy farmers' perception of biosecurity. Prev Vet Med 99:122-9. doi:10.1016/j.prevetmed.2011. 01.010

Kruger H, Thompson L, Clarke R et al (2009) Engaging in biosecurity: gap analysis. Canberra, ACT

Lane MB, Robinson CJ (2009) Institutional complexity and environmental management: the challenge of integration and the promise of large-scale collaboration. Aust J Environ Manag 16:16-24. doi:10. 1080/14486563.2009.9725213

Leith P, Vanclay F (2016) Placing science for natural resource management and climate variability: lessons from narratives of risk, place and identity. Sociol Rural 00:1-29. doi:10.1111/soru.12124

Mankad A (2012) Decentralised water systems: emotional influences on resource decision making. Environ Int 44:128-40. doi:10.1016/j. envint.2012.01.002

Manzo LC, Perkins DD (2006) Finding common ground: the importance of place attachment to community participation and planning. J Plan Lit 20:335-350

McCusker C, Carnevale PJ (1995) Framing in resource dilemmas: loss aversion and the moderating effects of sanctions. Organ Behav Hum Decis Process 61:190-201

Miles SB (2015) Foundations of community disaster resilience: well-being, identity, services, and capitals. Environ Hazard 1-19. doi: 10. 1080/17477891.2014.999018

Monroe MC (2003) Two avenues for encouraging conservation behaviors. Res Hum Ecol 10:113-125

Myers DG (2004) Theories of emotion, 7th edn. Worth Publishers, New York

Nicholls JG (1984) Achievement motivation: conceptions of ability, subjective experience, task choice, and performance. Psychol Rev 91: 328-346. doi:10.1037/0033-295X.91.3.328

Norris FH, Stevens SP, Pfefferbaum B et al (2008) Community resilience as a metaphor, theory, set of capacities, and strategy for disaster readiness. Am J Community Psychol 41:127-50. doi:10.1007/ s10464-007-9156-6

Öhlmér B, Olson K, Brehmer B (1998) Understanding farmers' decision making processes and improving managerial assistance. Agric Econ 18:273-290. doi:10.1016/S0169-5150(97)00052-2

Palmer S, Sully M, Fozdar F (2009) Farmers, animal disease reporting and the effect of trust: a study of West Australian sheep and cattle farmers. Rural Soc 19:32-48

Pannell DJ, Marshall GR, Barr N et al (2006) Understanding and promoting adoption of conservation practices by rural landholders. Aust J Exp Agric 46:1407-1424. doi:10.1071/EA05037

Peshin R, Vasanthakumar J, Kalra R (2009) Integrated pest management: innovation-development process. 1-29. doi: 10.1007/978-1-40208992-3

Plant Health Australia (2011) Government and plant industry cost sharing deed in respect of emergency plant pest responses. 258

Reimer AP, Thompson AW, Prokopy LS (2012) The multi-dimensional nature of environmental attitudes among farmers in Indiana: implications for conservation adoption. Agric Hum Values 29:29-40. doi: 10.1007/s10460-011-9308-Z

Robinson CJ, Smyth D, Whitehead PJ (2005) Bush tucker, bush pets, and bush threats: cooperative management of feral animals in Australia's
Kakadu National Park. Conserv Biol 19:1385-1391. doi:10.1111/j. 1523-1739.2005.00196.x

Rogers RW (1975) A protection motivation theory of fear appeals and attitude change. J Psychol 91:93-114

Rogers RW (1983) Cognitive and physiological processes in attitude change: a revised theory of protection motivation. In: Cacioppo J, Petty R (eds) Social Psychophysiology. Guilford Press, New York, pp 153-176

Rogers EM (2004) A prospective and retrospective look at the diffusion model. J Health Commun 9(Suppl 1):13-9. doi:10.1080/ 10810730490271449

Rogers RW, Mewborn CR (1976) Fear appeals and attitude change: effects of a threat's noxiousness, probability of occurrence, and the efficacy of coping responses. J Pers Soc Psychol 34:54-61

Roy Dutta D (2009) Self-efficacy of agricultural farmers: a case study. J Indian Acad Appl Psychol 35:323-328

Sarin RK, Weber M (1993) Effects of ambiguity in market experiments. Manag Sci 39:602-615

Schemann K, Taylor MR, Toribio JLML, Dhand NK (2011) Horse owners' biosecurity practices following the first equine influenza outbreak in Australia. Prev Vet Med 102:304-14. doi:10.1016/j. prevetmed.2011.08.002

Schultz PW (2000) Empathizing with nature: the effects of perspective taking on concern for environmental issues. J Soc Issues 56:391-406

Scottish Executive (2002) Codes of recommendations for the welfare of livestock: animal health and biosecurity

Simin M, Janković D (2014) Applicability of diffusion of innovation theory in organic agriculture. Econ Agric 2014:517-531

Stedman R (2002) Toward a social psychology of place. Environ Behav 34:561-581

Taylor M, Agho K, Griffin E (2008) Human impacts of equine influenza. Summary Report. Sydney

Thøgersen J (2003) Monetary incentives and recycling: behavioural and psychological reactions to a performance-dependent garbage fee. $\mathrm{J}$ Consum Policy 26:197-228

Toborn J (2011) Adoption of agricultural innovations, converging narratives, and the role of Swedish agricultural research for development. 46

Tversky A, Kahneman D (1981) The framing of decisions and the psychology of choice. Science 211(80- ):453-458

Valeeva NI, Lam TJGM, Hogeveen H (2007) Motivation of dairy farmers to improve mastitis management. J Dairy Sci 90:4466-4477. doi:10. 3168/jds.2007-0095

Valente TW, Rogers EM (1995) The origins and development of the diffusion of innovations paradigm as an example of scientific growth. Scei Commun 16:242-273

Vaske JJ, Kobrin KC (2001) Place attachment and environmentally responsible behavior. J Environ Educ 32:16-21

Wang T, Hennessy DA (2015) Strategic interactions among private and public efforts when preventing and stamping out a highly infectious animal disease. Am J Agric Econ 97:435-451. doi:10.1093/ajae/ aau119

Weber EU, Blais A-R, Betz NE (2002) A domain-specific risk-attitude scale: measuring risk perceptions and risk behaviors. J Behav Decis Mak 15:263-290. doi:10.1002/bdm.414

Wilkening EA (1950) A socio-psychological approach to the study of acceptance of innovations farming. Rural Sociol 15:352-364

Williams DR, Vaske JJ (2003) The measurement of place attachment: validity and generalizability of a psychometric approach. For Sci 49:830-840

Wu H, Mweemba L (2009) Environmental self-efficacy, attitude and behavior among small scale farmers in Zambia. Environ Dev Sustain 12:727-744. doi:10.1007/s10668-009-9221-4

Young JN, Coleman AL (1959) Neighbourhood norms and the adoption of farm practices.pdf. Rural Sociol 24:372-380 